\title{
EDITORIAL
}

\section{Volemic replacement during spinal cord injury patients.}

\author{
María Bermúdez ${ }^{1}$ \\ ${ }^{1}$ Servicio Anestesiología, Reanimación y Terapéutica del Dolor. Hospital Universitario Lucus Augusti. \\ Lugo. 27003. España.
}

\author{
Correspondence to: \\ María Bermúdez López, Servicio Anestesiología, Reanimación y Terapéutica del Dolor. \\ Hospital Universitario Lucus Augusti. \\ E-mail:majobl79@gmail.com
}

\section{Conflicts of interests \\ Nothing to declare}

\section{Acknowledgment}

None

Funding: This research did not receive any specific grant from funding agencies in the public, commercial or not-for profit sectors.

Keywords: acute spinal cord injury, fluid therapy, hemodynamic optimization.

These authors take responsibility for all aspects of the reliability and freedom from bias of the data presented and their discussed interpretation.

Central Eur J Clin Res 2019;2(1):1-2

Received: 01.04.2019, Accepted: 05.04.2019, Published: 12.04.2019

Copyright ( 2018 Central European Journal of Clinical Research. This is an open-access article distributed under the Creative Commons Attribution License, which permits unrestricted use, distribution, and reproduction in any medium, provided the original work is properly cited.

Acute traumatic spinal cord injury $(\mathrm{SCl})$ is frequently associated with systemic hypotension, which may be attributable to associated traumatic injuries with hypovolemia, direct severe spinal cord trauma itself, or a combination [1][2]. At the same time, the traumatic neurogenic shock is a rare but serious complication of $\mathrm{SCl}$. It is life-threatening and associates bradycardia and hypotension caused by a medullary trauma. Cardiovascular instability is a frequent complication of $\mathrm{SCl}$, especially when the upper thoracic and cervical cord is involved. Sympathetic denervation results in arteriolar dilation and the interruption of cardiac sympathetic innervations (T1-T4) promotes bradycardia and reduces myocardial contractility [3]. Neurogenic shock generally lasts from 1 to 3 weeks [3].

The principal clinical concern is to avoid secondary (irreversible) cord damage [3]. Ischemia of the spinal cord is thought to be one of the most important contributors to neuronal injury and neurological deficit after acute $\mathrm{SCl}$. For that reason, treatment of hypotension and resuscitation to maintain the mean arterial pressure at high-normal levels, 85 to $90 \mathrm{~mm} \mathrm{hg}$, for the first 7 days following an $\mathrm{SCl}$ is highly recommended [2][4][5]. Therefore, not only the surgical management, by relieving or preventing compression of neural structures; but also, the medical optimization of cord perfusion and oxygenation, may be associated with better neurologic results after $\mathrm{SCl}$ [3][4].

In this context it is essential the ICU monitoring which allows the early detection of 
hemodynamic instability, cardiac disturbances, pulmonary dysfunction, and hypoxemia [2]. Management of $\mathrm{SCl}$ is directed toward limiting secondary injury and maximizing neurologic recovery [3].

The hemodynamic monitoring and consequently fluid therapy in order to maintenance of the mean arterial pressure above $85 \mathrm{mmHg}$ reduces secondary complications [6]. Normally, a combination of fluid therapy with vasopressors is needed. The blood volume of patients with $\mathrm{SCl}$ is reduced by approximately $20 \%$ [7]. However, congestive heart failure may occur, particularly if fluids are administered injudiciously [3][8]. Therefore, the question still without answer: how much and which fluids? There is lack of studies comparing different managements.

A reasonable strategy is one in which 1)hypotension is rigorously avoided and 2)cord perfusion is optimized with volume expansion and blood pressure augmentation, so long as these interventions do not impact unfavorably on other organ systems [5]. At this point it is essential that the fluids are guided by invasive hemodynamic monitoring to avoid congestive heart failure, fluids should be titrated with particular attention to incremental changes in cardiac output and filling pressures [3]. In fact, Lehmann et al reported that episodic hypotension unrelated to hypovolemia was identified in $68 \%$ of severe cervical injuried patients, requiring the use of intravenous pressors in half [9]. Therefore, the fluid management in this patients is challenging and it is mandatory the use of cardiac, hemodynamic, and respiratory monitoring devices to detect cardiovascular dysfunction $n$ patients following acute spinal cord injury [2]. As a result, the goal-directed fluid therapy is essential in this clinical setting. Besides this, pulmonary artery catheterization or transesophageal echocardiography should be considered in the presence of severe hemodynamic compromise[2][5].

In the other hand, $\mathrm{SCl}$ is associated with a high prevalence of hyponatremia, which can cause various clinical symptoms and increase mortality. Various factors including traumatic brain injury with an abbreviated injury scale score $\geq 3$ and higher American Spinal Injury Association impairment scale, bradycardia, vasopressors, and nosocomial pneumonia. may be associated with hyponatremia in patients with acute $\mathrm{SCl}$. These factors can help clinicians identify and monitor SCl patients with a higher hyponatremia risk, and potentially help patients to avoid severe complications [10]. Consequently, hypoosmolar and glucose solutions should be avoided in the $\mathrm{SCl}$.

Finally, the volemic replacement during $\mathrm{SCl}$ has an important impact on the neurological outcome of these patients and deserves further study. Recommendations about hemodynamic optimization (PAM> $85 \mathrm{mmHg}$ ) have a potential benefit but the most appropriate threshold level of MAP and how to get it (farmacological strategy and fluid therapy) it is still unclear.

\section{References}

1. King BS, Gupta R, Narayan RK. The early assessment and intensive care unit management of patients with severe traumatic brain and spinal cord injuries. Surg Clin North Am. 2000;80(3):855-70.

2. Ryken TC, Hurlbert RJ, Hadley MN, Aarabi B, Dhall SS, Gelb DE, et al. The acute cardiopulmonary management of patients with cervical spinal cord injuries. Neurosurgery. 2013;72(SUPPL.2):84-92.

3. Stevens RD, Bhardwaj A, Kirsch JR, Mirski MA. Critical care and perioperative management in traumatic spinal cord injury. J Neurosurg Anesthesiol. 2003;15(3):215-29.

4. Walters BC, Hadley MN, Hurlbert RJ, Aarabi B, Dhall SS, Gelb DE, et al. Guidelines for the management of acute cervical spine and spinal cord injuries: 2013 update. Neurosurgery60 ()(pp 82-91), 2013Date Publ August 2013. 2013;(SUPPL. 1):82-91.

5. Hadley MN, Walters BC, Grabb PA, Oyesiku NM, Przybylski GJ, Resnick DK, et al. Blood Pressure Management after Acute Spinal Cord Injury. Neurosurgery. 2002 Mar 1;50(suppl_3):S58-62.

6. Vaccaro $A \bar{R}$, Hulbert RJ, Patel $A A$, Fisher C, Dvorak M, Lehman RA, et al. The Subaxial Cervical Spine Injury Classification System. Spine (Phila Pa 1976). 2007 Oct 1;32(21):2365-74.

7. Allman K, Wilson I, editors. Oxford Handbook of Anaesthesia. Oxford University Press; 2011.

8. Mackenzie CF, Shin B, Krishnaprasad D, McCormack F, Illingworth W. Assessment of cardiac and respiratory function during surgery on patients with acute quadriplegia. J Neurosurg. 1985 Jun;62(6):843-9.

9. Lehmann KG, Lane JG, Piepmeier JM, Batsford WP. Cardiovascular abnormalities accompanying acute spinal cord injury in humans: incidence, time course and severity. J Am Coll Cardiol. 1987 Jul;10(1):46-52.

10. Ohbe H, Koakutsu T, Kushimoto S. Analysis of risk factors for hyponatremia in patients with acute spinal cord injury: a retrospective single-institution study in Japan. Spinal Cord. 2019 Mar 16;57(3):240-6. 